Gut, $1985,26,718-723$

\title{
Distal transposition of rat caecum does not render it susceptible to carcinogenesis
}

\author{
J B RAINEY, M MAEDA, AND R C N WILLIAMSON \\ From the University Department of Surgery, Bristol Royal Infirmary, Bristol
}

SUMMARY As the relative resistance of rat caecum to chemical carcinogens could reflect its luminal environment, caecal mucosa was exposed to the distal faecal stream in male Sprague-Dawley rats $(n=50)$ previously treated with azoxymethane (total dose $90 \mathrm{mg} / \mathrm{kg} \mathrm{sc}$ ). After colonic transection at the pelvic brim, the caecum was inserted isoperistaltically between colocaecal and caecorectal anastomoses $(n=30)$; an ileocolic anastomosis restored intestinal continuity. Controls $(n=20)$ had transection and reanastomosis at equivalent points of the bowel, plus caecotomy and resuture. Caecal crypt cell production rate, as determined stathmokinetically at 28 weeks, was not consistently affected by transposition. No tumours developed in either transposed or orthotopic caecum, apart from three suture-line tumours found at the caecotomy site in controls. The colonic tumour yield in controls $(1 \cdot 4 \pm 0 \cdot 3$ per rat : mean $\pm S E M)$ matched that after transposition $(1 \cdot 5 \pm 0 \cdot 2)$, but anastomotic tumours were twice as common after transposition $(p<0 \cdot 05)$ and rectal tumours were increased four-fold $(p<0 \cdot 05)$. The caecum remains resistant to carcinogenesis despite transposition to a distal colonic environment. Local epithelial defence mechanisms are more important than luminal contents in maintaining this resistance.

Like its human counterpart the appendix, the rat caecum is relatively resistant to carcinogenesis. Several experimental studies show a much lower incidence of tumours at this site than in the rest of the large intestine. ${ }^{1-5}$ In some reports the caecum has been completely spared, despite appreciable numbers of tumours arising elsewhere in the intestinal tract, particularly the distal colon. ${ }^{6-8}$ Surgical shortening of the gut by resection or bypass is a powerful stimulus to adaptive hyperplasia and carcinogenesis in the residual functioning bowel; but while it appears to promote caecal hyperplasia, its effect on caecal carcinogenesis is minimal. ${ }^{89}$

The luminal environment of the caecal mucosa might be responsible for maintaining this resistance to neoplasia. The composition, bulk, transit time and bacterial population of the faeces passing through the caecum could each be important in this respect. This study was designed to test the effect of exposure to the distal faecal stream on the proliferative state of the caecal mucosa and its susceptibility to chemically induced carcinogenesis. Because operation could affect body weight and intestinal blood flow, caecal transposition was carried out after the azoxymethane injections to

Address for correspondence: Professor R C N Williamson. University Department of Surgery, Bristol Royal Infirmary, Bristol BS2 8HW

Received for publication 3 August 1984 avoid differences in the dose of carcinogen and its bloodborne delivery to the adapting bowel.

\section{Methods}

EXPERIMENTAL ANIMALS

Fifty male Sprague-Dawley rats (Olac SD, Bicester, Oxon, England) weighing 100-140 g were received into the animal house one week before the start of the experiment and were randomised to two groups. They were fed standard rat chow (Oxoid Breeding Diet, Styles and Co Ltd, Bewdley, Worcs) and water ad libitum. Animal quarters were lit in alternate 12-hour cycles. Rats were weighed weekly throughout the experiment. All animals received weekly subcutaneous injections of azoxymethane (Ash Stevens Inc, Detroit, Michigan, USA) 15 $\mathrm{mg} / \mathrm{kg}$ for six weeks. Each rat was submitted to operation 7-12 days after the last injection of carcinogen.

\section{SURGICAL OPERATIONS}

Operations were carried out under light ether anaesthesia. Continuous $6 / 0$ silk sutures were used for intestinal anastomoses.

Caecal transposition $(n=30)$ was performed as follows. The ascending colon and terminal ileum were transected $0.5 \mathrm{~cm}$ from their junctions with the 
caecum, and the ileal stump attached to the caecum was ligated with a $3 / 0$ silk suture (Fig. 1). The distal colon was transected at the pelvic brim, and the caecum was mobilised on its blood supply and inserted in an isoperistaltic direction between the cut ends. The stump of the ascending colon was anastomosed to the rectum. A large part of the caecum is normally a blind loop, so to expose its entire mucosa evenly to distal colonic content, the descending colon was anastomosed to an apical caecotomy rather than to the ileal stump. An ileocolic anastomosis restored intestinal continuity.

Sham transposition $(n=20)$ involved transection and reanastomosis at equivalent points of the proximal and distal colon, with caecotomy and resuture at the caecal apex (Fig. 1).

At the end of each operation $0.25 \mathrm{mg}$ vitamin $\mathrm{K}$ was administered intramuscularly to prevent the troublesome postoperative bleeding previously encountered in young Sprague-Dawley rats. ${ }^{4}$

\section{NECROPSY SPECIMENS}

Rats were regularly examined for evidence of tumour development and were killed when moribund or at the end of 28 weeks. At necropsy the entire intestinal tract was excised. The following segments were thoroughly flushed with cold saline to remove all content: duodenum, jejunoileum, caecum, colon (proximal to transposed caecum or between anastomoses) and rectum. The surface area of the caecum was estimated as previously described, ${ }^{8}$ and the length of the other intestinal segments was determined by suspension with a constant weight against a ruler. The weights of the liver, kidneys, and spleen were also recorded. Intestinal segments were opened, and the number, size, and position of all tumours were recorded. The tumours were excised, and the remaining bowel was blotted dry and weighed. All tumours were fixed in $10 \%$ formalin before preparation of $5 \mu \mathrm{m}$ histological sections, which were stained with haematoxylin and eosin.

In addition, six rats in each group were given vincristine $(1 \mathrm{mg} / \mathrm{kg}$ ip) and were killed at 30 minute intervals thereafter up to 180 minutes. Necropsy was carried out as above, but after excision of tumours, the entire large bowel and the terminal $10 \mathrm{~cm}$ of ileum, were fixed in Carnoy's solution. After two to six hours specimens were transferred to $70 \%$ alcohol for preservation and subsequent staining with Schiff's reagent.

The crypt cell production rate at various points of the bowel could then be estimated stathmokinetically, as described by Wright. ${ }^{10}$ For each segment of bowel examined the number of arrested metaphases was counted in 10 individually micro-
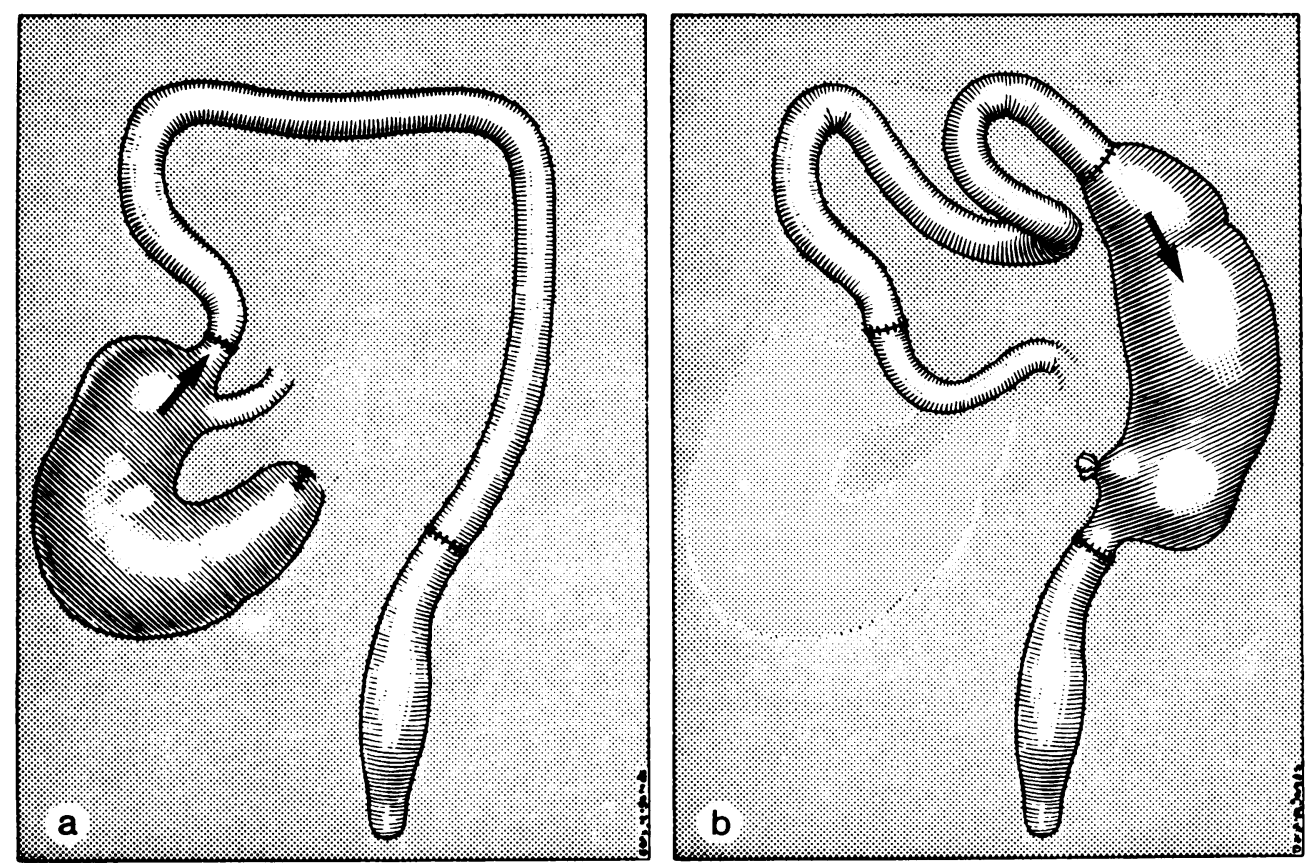

Fig. 1 Operations: $a=$ sham caecal transposition (controls), $b=$ caecal transposition. 
dissected crypts per specimen and was plotted against time after injection of vincristine. The slope of the regression line fitted to this data represented the rate of accumulation of arrested metaphases that is, the crypt cell production rate (CCPR).

\section{STATISTICS}

All data were analysed for statistical significance using Student's $t$ test.

\section{Results}

\section{MORTALITY RATE}

There were three early deaths $(6 \%)$ from anaesthetic overdose. Another six rats $(12 \%)$ died before they could be killed, three from adhesion obstruction and three from intestinal cancer. Premature mortality rates were $20 \%$ after caecal transposition (24 survivors) and $15 \%$ after sham transposition (17 survivors).

\section{BODY WEIGHT}

After sham transposition, rats lost $3 \%$ of body weight during the first 48 hours but regained their original weight by the end of the first postoperative week. After caecal transposition, rats continued to lose weight $(7 \%)$ during the first week and only regained their preoperative weight at the end of the second week: Although they consistently weighed a little less than shams throughout the remainder of the experiment, their weight was not significantly different at time of death $(557 \pm 12 \mathrm{~g} v s 87 \pm 6 \mathrm{~g}$ : mean \pm SEM).

\section{INTESTINAL ADAPTATION}

The surface area of the transposed caecum was $21 \%$ greater than that of the orthotopic caecum (Table 1). In the colorectum both total weight and total length were greater after transposition than after sham transposition. No differences were found in the length and wet weight of the duodenum and

Table 1 Surface area and weight of transposed and orthotopic caecum and length and weight of colorectum in the two groups. ${ }^{* *} p<0.01{ }^{*} p<0.05$

\begin{tabular}{llcc}
\hline & & $\begin{array}{l}\text { Controls } \\
(\text { mean } \pm \text { SEM })\end{array}$ & $\begin{array}{l}\text { Transposition } \\
(\text { mean } \pm \text { SEM })\end{array}$ \\
\hline Caecum & $\begin{array}{l}\text { Surface area } \\
\left(\mathrm{cm}^{2}\right)\end{array}$ & $41 \cdot 4 \pm 2 \cdot 0$ & $50 \cdot 0 \pm 2 \cdot 0^{* *}$ \\
& $\begin{array}{l}\text { Weight } \\
\text { (g) }\end{array}$ & $3 \cdot 1 \pm 0 \cdot 2$ & $3 \cdot 6 \pm 0 \cdot 2$ \\
Colorectum & $\begin{array}{l}\text { Length } \\
(\mathrm{cm})\end{array}$ & $23 \cdot 4 \pm 0 \cdot 4$ & $25 \cdot 2 \pm 0 \cdot 4^{*}$ \\
& $\begin{array}{l}\text { Weight } \\
(\mathrm{g})\end{array}$ & $2 \cdot 4 \pm 0 \cdot 1$ & $3 \cdot 0 \pm 0 \cdot 1^{*}$ \\
\hline
\end{tabular}

jejunoileum nor in the weights of the liver, kidneys and spleen. Crypt cell production rates in the colon were similar in each group (Table 2). Transposition increased CCPR in the terminal ileum by $31 \%$ and reduced it in the rectum by $62 \%$. No consistent effect was observed in the caecum.

\section{INTESTINAL TUMOURS}

There were no tumours in the transposed caecum, but three developed in the orthotopic caecum at the site of caecotomy closure (Fig. 2). Suture-line tumours were common elsewhere, particularly at the colocaecal and caecorectal anastomoses after transposition and at the distal colonic anastomosis in shams. The overall yield of suture-line cancers after transposition $(1.8 \pm 0.2$ per rat: mean \pm SEM) was twice that in shams $(0.9 \pm 0.3 ; p<0.05)$. The yield of non-anastomotic colonic tumours in the shams $(1 \cdot 4 \pm 0 \cdot 3)$ matched that after transposition $(1 \cdot 5 \pm 0 \cdot 2)$, but their distribution was different (Fig. $2)$. Tumour yield in the rectum was increased four-fold from $0 \cdot 2 \pm 0 \cdot 1$ in shams to $0 \cdot 8 \pm 0 \cdot 2$ in the transposition group $(p<0 \cdot 05)$.

Irrespective of operation tumours were also found in the duodenum (seven rats), upper jejunum (two), external auditory canal (one) and at metastatic sites (13). Histological types of benign and malignant neoplasms were as previously described. ${ }^{6-8}$

\section{Discussion}

Rat caecum maintains its innate resistance to azoxymethane-induced carcinogenesis when subsequently exposed to the luminal environment of the distal colon, where tumours most commonly arise. Any differences between these two regions in respect of faecal bulk or contents, such as bile acids and bacteria, would surely have been lessened if not abolished by caecal transposition. In determining susceptibility to neoplasia, therefore, luminal influences seem less important than the inherent characteristics of the mucosa, assuming that they exert their effect at the stage of promotion rather

Table 2 Crypt cell production rates (cells/crypt/hour) after sham caecal transposition (controls) and after caecal transposition (means $\pm S E M$ ). ${ }^{*} p<0.02{ }^{* *} p<0.01$.

\begin{tabular}{lrc}
\hline & Controls & Transposition \\
\hline Ileum & $10 \cdot 6 \pm 0 \cdot 4$ & $13 \cdot 9 \pm 1 \cdot 0^{*}$ \\
Caecal apex & $6 \cdot 9 \pm 2 \cdot 2$ & $9 \cdot 5 \pm 1 \cdot 2$ \\
Distal caecum & $13 \cdot 9 \pm 0 \cdot 5$ & $5 \cdot 7 \pm 3 \cdot 3$ \\
Proximal colon & $12 \cdot 5 \pm 3 \cdot 1$ & $10.0 \pm 1 \cdot 9$ \\
Distal colon & $9 \cdot 4 \pm 0 \cdot 8$ & $11 \cdot 5 \pm 4 \cdot 5$ \\
Rectum & $13 \cdot 8 \pm 2 \cdot 0$ & $5 \cdot 2 \pm 1 \cdot 5^{* *}$ \\
\hline
\end{tabular}



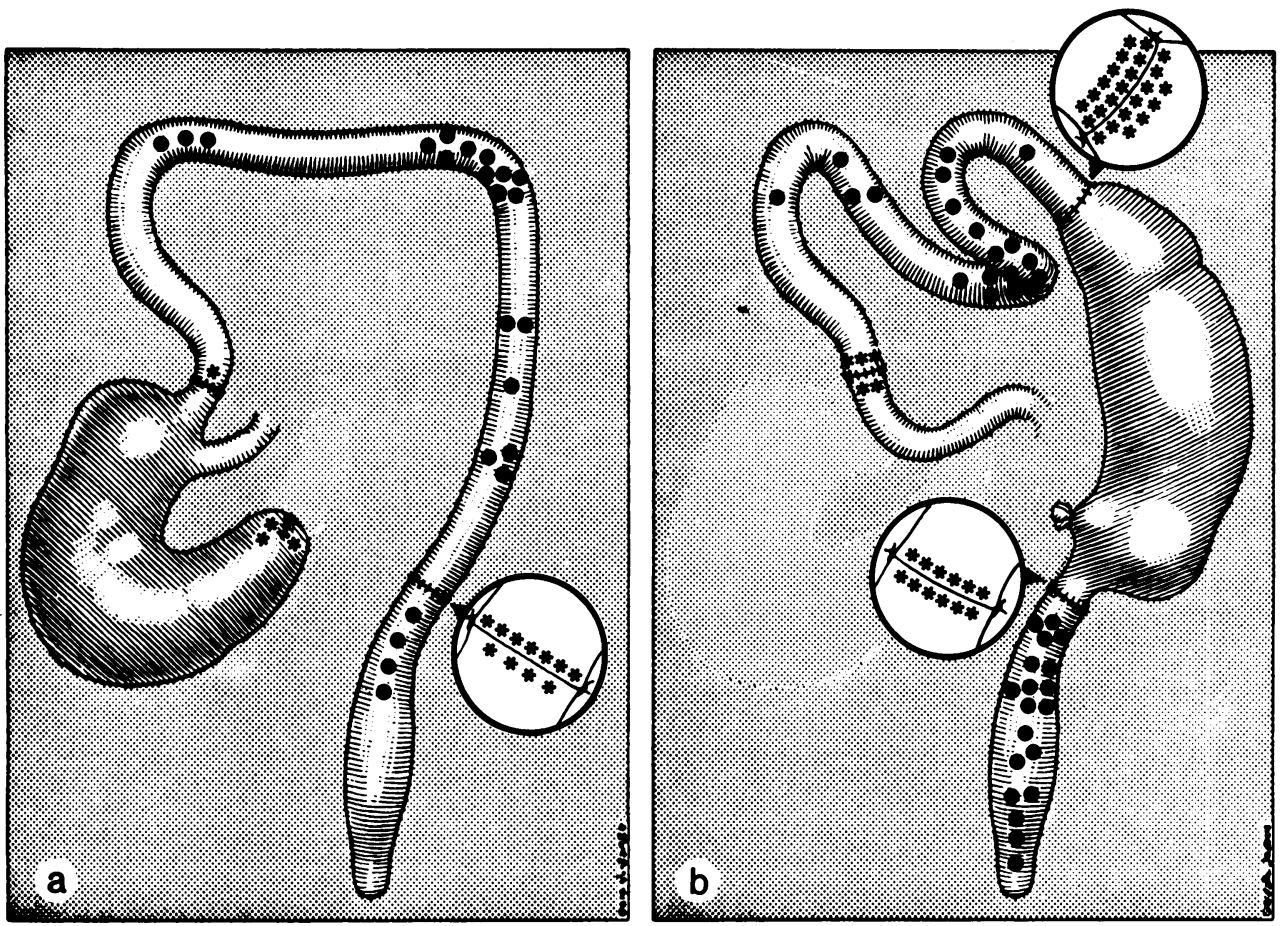

Fig. 2 Tumour distribution: $a=$ controls (17 rats), $b=$ caecal transposition (24 rats). Non-anastomotic tumours represented by and anastomotic tumours by $\star$.

than initiation. This assumption is supported by previous studies showing that both surgical operations and the administration of bile acids enhance the development of neoplasia in intestinal mucosa already primed by azoxymethane; $;^{3-5} 1112$ large numbers of suture-line tumours in the present study further illustrate this phenomenon. When operation precedes carcinogen and results in increased tumour yields, ${ }^{236-8}$ either initiation or promotion could have been affected as postoperative hyperplasia is prolonged. ${ }^{9}$ Indeed, the timing of operation and carcinogen treatment does not appear to alter the result, ${ }^{313}$ provided postoperative weight loss is not excessive. ${ }^{411}$ Not only carcinogenesis but initiation itself is probably a multistep process, so that it is very difficult to determine which particular step(s) is susceptible to changes in the luminal environment. ${ }^{14}$

The caecum shares its relative resistance to neoplasia with the distal small bowel. ${ }^{9}$ Segments of mid-jejunum transposed to the colon do not develop cancer, even though several tumours can be induced in the adjacent large bowel. ${ }^{15}{ }^{16}$ Conversely, colonic segments transposed to the small bowel retain their normal susceptibility to carcinogenesis.
Although the luminal environment appears to play little part in the resistance of some intestinal segments to cancer it does have an important regulatory function in susceptible bowel. Defunctioned colon develops fewer tumours than colon in continuity. ${ }^{17}{ }^{18}$ In contrast, increasing the faecal concentration of bile acids either by pancreatobiliary diversion to mid-small bowel or by direct oral or intrarectal administration enhances colorectal carcinogenesis. ${ }^{3121920}$ It is likely, however, that the presence and composition of the luminal contents affect carcinogenesis by altering epithelial cell turnover. Defunctioned colon rapidly becomes hypoplastic, whereas distal diversion of pancreatobiliary secretions produces adaptive hyperplasia downstream. ${ }^{21}{ }^{22}$ Likewise surgical shortening of the small intestine by resection or bypass increases the concentration of nutrients and upper gastrointestinal secretions entering the distal gut and causes hyperplasia and increased neoplasia in the colon (but not the ileum). ${ }^{9}$ Intrarectal instillation of bile acids probably induces mucosal inflammation and consequent hyperplasia as a prelude to the promotion of carcinogenesis. ${ }^{12}$

Adaptive hyperplasia is no more able to overcome 
the resistance of insusceptible bowel to experimental carcinogenesis than altered luminal contents. The ileum becomes intensely hyperplastic after jejunal resection, pancreatobiliary diversion or subtotal colectomy, but virtually no ileal tumours develop whether operation precedes or follows the administration of azoxymethane..$^{36711}$ Resistance to carcinogenesis may be attributable to local epithelial defence mechanisms or to the absence of enzymes needed to synthesise the ultimate carcinogen. ${ }^{9}{ }^{15}$ Similar protective mechanisms could operate in the rat caecum. Although transposition produces relatively minor fluctuations in caecal CCPR, ileal resection stimulates caecal growth without altering tumour yields. ${ }^{8}$

The finding of three suture-line tumours at the apex of the caecum in controls is interesting. In a similar experiment Pozharisski found that the presence of a non-absorbable suture placed through the caecal wall enhanced caecal carcinogenesis, ${ }^{1}$ though to a much greater extent. Thus local inflammation and hyperplasia seem more important in carcinogenesis than faecal composition. Sutureline tumours are a common feature both in patients surviving partial colectomy $\mathrm{y}^{23}$ and in rats given chemical carcinogens either pre- or postoperatively. ${ }^{3913}$ Anastomotic recurrence in man could reflect chronic inflammation and hyperplasia caused by the suture material, inadequate resection, or implantation of viable cancer cells at operation. ${ }^{23-25}$ In both man and the rat anastomoses involving distal colon are at greater risk than those involving proximal colon or ileum, ${ }^{13}{ }^{26}$ presumably because of the left-sided predominance of largebowel cancer in each species. In the present study anastomotic tumours were more frequent after caecal transpositon, in which two anastomoses contained a distal colonic component, than after sham transposition, when only one anastomosis had such a component.

Caecal transposition produced a slight increase in the length and wet weight of the colon and in the surface area of the caecum, without corresponding increases in cell proliferation. Perhaps an alteration in faecal bulk produced dilatation of the heterotopic caecum and consequent back pressure, leading to muscular hypertrophy. The increased tumour yield found in the rectum distal to the transposed caecum, despite paradoxical hypoplasia is puzzling. Insertion of a large reservoir just proximal to this segment may have altered faecal composition in such a way as to facilitate tumour growth while partly usurping rectal function and thus depressing its mucosal cell turnover.

This study was supported by grants from the Cancer
Research Campaign and the South Western Regional Health Authority. We thank $\mathrm{Mr} \mathrm{N}$ Peachey and Mrs C Williams for technical assistance. Figures were supplied by the Department of Medical Illustration, Bristol Royal Infirmary.

\section{References}

1 Pozharisski KM. The significance of nonspecific injury for colon carcinogenesis in rats. Cancer Res 1975; 35: 3824-30.

2 Oscarson JEA, Veen HF, Ross JS, Malt RA. Ileal resection potentiates 1,2-dimethylhydrazine-induced colonic carcinogenesis. Ann Surg 1979; 189: 503-8.

3 Williamson RCN, Bauer FLR, Ross JS, Watkins JB, Malt RA. Enhanced colonic carcinogenesis with azoxymethane in rats after pancreaticobiliary diversion to mid small bowel. Gastroenterology 1979; 76: 1386-92.

4 Bristol JB, Davies PW, Williamson RCN. Subtotal jejuno-ileal bypass enhances experimental colorectal carcinogenesis unless weight reduction is profound. In: Malt RA and Williamson RCN, eds. Colonic carcinogenesis, Lancaster: MTP Press Ltd, 1982: 275-81.

5 Scudamore $\mathrm{CH}$, Freeman $\mathrm{HJ}$. Effects of small bowel transection, resection, or bypass in 1,2-dimethylhydrazine-induced rat intestinal neoplasia. Gastroenterology 1983; 84: 725-31.

6 Williamson RCN, Bauer FLR, Ross JS, Oscarson JEA, Malt RA. Promotion of azoxymethane-induced colonic neoplasia by resection of the proximal small bowel. Cancer Res 1978; 38: 3212-7.

7 Williamson RCN, Bauer FLR, Terpstra OT, Ross JS, Malt RA. Contrasting effects of subtotal enteric bypass, enterectomy, and colectomy on azoxymethane-induced intestinal carcinogenesis. Cancer Res 1980; 40: 538-43.

8 Williamson RCN, Lyndon PJ, Tudway AJC. Effects of anticoagulation and ileal resection on the development and spread of experimental intestinal carcinomas. $\mathrm{Br} \mathrm{J}$ Cancer 1980; 42: 85-94.

9 Williamson RCN. Postoperative adaptation in the aetiology of intestinal cancer. In: Robinson JWL, Dowling RH, Riecken E-O, eds. Mechanisms of intestinal adaptation, Lancaster: MTP Press Ltd, 1982: 621-34.

10 Wright NA. The experimental analysis of changes in the proliferative and morphological status in studies on the intestine. Scand J Gastroenterol 1982; 17: (74): 3-10.

11 Bristol JB, Wells M, Williamson RCN. Adaptation to jejunoileal bypass promotes experimental colorectal carcinogenesis. Br J Surg 1984; 71: 123-6.

12 Rainey JB, Maeda M, Williams C, Williamson RCN. The cocarcinogenic effect of intrarectal deoxycholate in rats is reduced by oral metronidazole. Br J Cancer 1984; 49: 631-6.

13 Williamson RCN, Davies PW, Bristol JB, Wells M. Intestinal adaptation and experimental carcinogenesis after partial colectomy: increased tumour yields are 
confined to the anastomosis. Gut 1982; 23: 316-25.

14 Cayama E, Tsuda H, Sarma DSR, Farber E. Initiation of chemical carcinogenesis requires cell proliferation. Nature 1978; 275: 60-2.

15 Gennaro AR, Villanueva R, Sukonthaman $Y$, Vathanoption V, Rosemond GP. Chemical carcinogenesis in transposed intestinal segments. Cancer Res 1973; 33: 536-41.

16 Celik C, Mittelman A, Paolini NS, Lewis D, Evans JT. Effects of 1,2-symmetrical dimethylhydrazine on jejunocolic transposition in Sprague-Dawley rats. Cancer Res 1981; 41: 2908-11.

17 Campbell RL, Singh DV, Nigro ND. Importance of the fecal stream on the induction of colon tumours by azoxymethane in rats. Cancer Res 1975; 35: 1369-71.

18 Rainey JB, Davies PW, Bristol JB, Williamson RCN. Adaptation and carcinogenesis in defunctioned rat colon: divergent effects of faeces and bile acids. $\mathrm{Br} J$ Cancer 1983; 48: 477-85.

19 Cohen BI, Raicht RF, Deschner EE, Takahashi M, Sarwal AN, Fazzini E. Effect of cholic acid feeding on $\mathrm{N}$-methyl-N-nitrosourea-induced colonic tumours and cell kinetics in rats. J Natl Cancer Inst 1980; 64: 573-8.
20 Reddy BS, Watanabe K, Weisburger JH, Wynder EL. Promoting effect of bile acids in colon carcinogenesis in germ-free and conventional F344 rats. Cancer Res 1977; 37: 3238-42.

21 Terpstra OT, Dahl EP, Williamson RCN, Ross JS, Malt RA. Colostomy closure promotes cell proliferation and dimethylhydrazine-induced carcinogenesis in rat distal colon. Gastroenterology 1981; 81: 475-80.

22 Williamson RCN, Bauer FLR, Ross JS, Malt RA. Proximal enterectomy stimulates distal hyperplasia more than bypass or pancreatobiliary diversion. Gastroenterology 1978; 74: 16-23.

23 Cohn I Jr. Implantation in cancer of the colon. Surg Gynecol Obstet 1967; 124: 501-8.

24 Rosenberg IL. The aetiology of colonic suture-line recurrence. Ann $R$ Coll Surg Engl 1979; 61: 251-7.

25 Umpleby HC, Fermor B, Symes MO, Williamson RCN. Viability of exfoliated colorectal carcinoma cells. Br J Surg 1984; 9: 659-63.

26 Wright HK, Cleveland JC. The low recurrence rate of colonic carcinoma in ileocolic anastomoses. Surg Gynecol Obstet 1969; 129: 960-2. 